\title{
Teaching Foresight and the Future
}

\author{
Erran $\mathrm{Carmel}^{1}$, Michel Avital ${ }^{2}$, Paul Gray ${ }_{5}^{3}$, Jannis Kallinikos ${ }^{4}$, \\ and John Leslie King ${ }^{5}$ \\ ${ }^{1}$ American University, Washington, DC U.S.A. \\ carmel@american.edu \\ ${ }^{2}$ University of Amsterdam, Amsterdam, The Netherlands \\ avital@uva.nl \\ ${ }^{3}$ Claremont Graduate University, Claremont, CA U.S.A. \\ paul.gray@cgu.edu \\ ${ }^{4}$ London School of Economics, London, UK \\ j.kallinikos@lse.ac.uk \\ ${ }^{5}$ University of Michigan, Ann Arbor, MI U.S.A. \\ jlking@umich.edu
}

\begin{abstract}
We train students as retrospective observers who specialize in evidence-based post hoc analysis. Building on action research and a cry for relevance, we witness the emergence of engaged scholarship and focus on the present and ongoing affairs. However, the future appears to be virtually neglected in the IS management curricula and organizational studies. In keeping with the theme of the meeting, the objective of the panel is to demonstrate the relevance of foresight and future in our curriculum and its critical role in nurturing the next generation.
\end{abstract}

Keywords: Futures studies, strategic foresight, prospective thinking, curriculum development, teaching information systems.

\section{Introduction}

Based in the sciences, we train students as retrospective observers who specialize in evidence-based post hoc analysis. Building on action research and a cry for relevance, we witness the emergence of engaged scholarship and focus on the present and ongoing affairs. However, the future appears to be virtually neglected in information systems management curricula and organizational studies. Dealing with the future is considered by many to be something between speculation and reading tea leaves. In keeping with the theme of the meeting, the objective of the panel is to tear down the myth and demonstrate not only the relevance of foresight and analysis of the future in our curriculum but also its critical role in nurturing the next generation.

We live the future. Students love dabbling in it. Faculty members in other disciplines thrive teaching it. Futures Studies is a discipline with its own methodologies that is taught in social science programs around the world. Sometimes it is its own discipline, as is the case with Turku's Finland Futures Research Centre. The Institute for Alternative Futures (in the United States) lists 18 futures or foresight graduate programs around the world (see http://www.fernweb.org). Many of us 
teach information systems in business schools, where teaching futures thinking has been remarkably sparse ${ }^{1}$, perhaps because IS faculty assume that futures thinking is part of the epistemology of business strategy and the IS capstone courses. In general, the discipline of Futures Studies never progressed beyond a niche discipline.

\section{Controversy}

The panelists will take opposing yet complementary positions with respect to the role of futures studies in the IS curriculum. They will argue that

1. Futures studies should be taught in independent courses.

2. The area of futures should be best infused into other courses, such as IS strategy and as a tool for doctoral research.

3. Futures techniques have advanced to the point where they are taken seriously as a scholarly environment in other fields but technology transfer has not yet reached the point where these techniques can be widely adopted in the IS field.

\section{Panel Structure}

The panel topic is intended to generate responses to several specific questions. After a brief introduction by the panel moderator, the panelists will present short overviews in response to guiding questions that aim to contextualize the discussion and raise core issues. Specifically, panelists will be asked to draw on their experience in both the futures and IS fields to answer two initial questions:

- Why should we deal with the future in the IS curriculum?

- What methodologies can be used in the classroom environment for learning about the IS future and the effect of ICT on possible futures?

Then the discussion will move to a forward-looking perspective. Questions for this portion of the panel discussion are

- What IS research topics and domains would best be illuminated by futures research?

- Should we entrust only Forrester and Gartner with forecasting and understanding future technologies and environments?

The panel will conclude with a deliberation among the panelists and facilitated discussion with the audience. Examples of expected questions and topics include

- Are we seriously suggesting gut feel, crystal balls, tea leaves, and palm reading as appropriate approaches?

- Since futures studies are both quantitative and qualitative, should they be part of a course in analytics, or one about the social side of information systems, or both?

- How should we infuse or mesh futures studies in current IS courses?

- Should we deal with the future in a standalone course? Can it be done? Should the course be interdisciplinary in business schools?

- What is the future of Futures Studies as a discipline?

${ }^{1}$ With some notable exceptions, for example, in 2009 the University of Notre Dame became the first undergraduate business program requiring all business students to take a foresight course. 


\section{Panelists}

Michel Avital, Associate Professor at the University of Amsterdam and Visiting Professor at Viktoria Institute. Building on his interest in how information technology promotes innovation and extraordinary outcomes, Michel has studied and published articles on topics such as design, creativity, innovation, generative systems, collaboration and competition, green IT and sustainable value, positive organizational scholarship, and appreciative inquiry. In lieu of prediction, he relies on a constructive approach that links positive image with positive action. That is, the more collectives or individuals accustom to dealing with the future and to nurturing desired scenarios, the more likely they are to realize them. Michel designs courses with a prospective orientation and regularly incorporates elements of envisioning and future thinking into his graduate and post-graduate classes.

Erran Carmel (panel moderator), Professor of Information Technology and International Business Research Professor at the Kogod School of Business, American University. He is a recognized thought leader on the globalization of technology work and offshoring. He began teaching the MBA course Future \& Foresight in 2010.

Paul Gray, Emeritus Professor at Claremont Graduate University, is one of the early members of the Association for Information Systems, and a recipient of the LEO Award for Lifetime Achievement. Before retiring, Paul taught Futures as part of courses and IS doctoral seminars. He was a member of the Center for Futures Research at the University of Southern California from 1972 to 1980 where he conducted several futures studies. He has published on the future of IS. He is particularly concerned with IS researchers taking a futures perspective on the field so that we lead the thinking about the information systems future rather than depending on the opinions of consulting firms.

Jannis Kallinikos, Professor in the Department of Management at the London School of Economics. Recent publications include the The Consequences of Information: Institutional Implications of Technological Change (Elgar, 2006), and Governing through Technology: Information Artefacts and Social Practice (Palgrave, MacMillan, 2010). Both of his books and other recent writings deal extensively with the technological and social processes that shape the future, paying attention to how the diffusion of information and digital content are negotiating the functional habitat of organizations and the patterns of everyday living.

John Leslie King, Vice Provost for Strategy, and W. W. Bishop Professor in the School of Information at the University of Michigan. His research focuses on the relationship between technical change and social change, especially the transforming role of information technology in highly institutionalized production sectors such as transport, health, education, financial services, and government. The best predictor of the future is the past, for the simple reason that it is the only predictor. But as Marx said, people don't create the future as they please. The trick lies in seeing the persistent features of the world, the patterns, and figuring out where things are likely to go. The great ice hockey star Wayne Gretzky summed it up well: skate to where the puck is going to be. It's easier said than done, but it can be done. 